\title{
Assessment of Knowledge and Awareness Regarding Dental Home among Pediatric Residents in Vadodara City, Gujarat, India: A Cross-sectional Study
}

\author{
Srushti Vaidya ${ }^{1}$, Seema Bargale ${ }^{2}$, Bhavna Dave ${ }^{3}$, Anshula Deshpande ${ }^{4}$, Gaurav Chawda ${ }^{5}$, Paridhi Shah ${ }^{6}$
}

\begin{abstract}
Introduction: The dental home is inclusive of all aspects of oral health that results from the interaction of the patient, parents, dentists, and pediatricians. Pediatricians being the first point of contact are considered to be in a unique position to diagnose oral diseases early and are expected to stay updated with the concept of dental home.

Materials and methods: A cross-sectional survey study design was conducted among 60 pediatric residents in two medical institutes. A questionnaire comprising 12 questions was distributed and they were asked to fill the proforma. Descriptive statistical analysis was done.

Results: One hundred percent samples favored promoting oral health and spread awareness about the concept of dental home. About $70 \%$ of the pediatric residents from a private university and $60 \%$ of the pediatric residents from a public university examined the oral cavity as a part of their routine oral examination. About $56.7 \%$ of the residents from a private university and $40 \%$ of the residents from a public university discussed about oral health with their parents. About $60 \%$ of the residents from a private university and $53.3 \%$ of the residents from a public university were aware of the presence of a dental home in their institutes. About $63.3 \%$ of the residents from a private university and $46.6 \%$ of the residents from a public university were aware of the ideal time to visit a dental home for the first time.

Conclusion: Awareness of the presence of dental home was more in residents from a private university. Referral to the dental home was higher by private university residents. There exists a lack of knowledge and understanding regarding the concept of dental home among the pediatric residents of Vadodara city.

Keywords: Dental home, Pediatric residents, Primary care.

Journal of South Asian Association of Pediatric Dentistry (2019): 10.5005/jp-journals-10077-3021
\end{abstract}

\section{INTRODUCTION}

Vadodara is the third largest city in Western Indian state of Gujarat and has a population of 20.7 lakhs according to 2010-11 census reports. ${ }^{1}$ Currently, 1.85 lakh children are under 6 years of age. A large population of which suffers from the most common chronic disease, dental decay which is by and large preventable. Ideally, the steps to prevent decay should begin prenatally by giving proper counseling regarding oral hygiene practices. This should be continued with a young child where the first visit should be established no longer than 12 months of age.

The concept of the "dental home" is derived from the American Academy of Pediatrics concept of the "medical home" and is new to most of the dental professionals. The American Academy of Pediatric Dentistry (AAPD) initially adopted a policy in 2001 and further defined the dental home in 2006 as "the ongoing relationship between the dentist and the patient, inclusive of all aspects of oral health care delivered in a comprehensive, continuously accessible, coordinated, and family-centered way". Establishment of a dental home begins no later than 12 months of age and includes referral to dental specialists when appropriate. ${ }^{2}$ The AAPD concept of dental home aims to begin early in terms of dental care with an emphasis on primordial and primary prevention and promotion of dental health concept. ${ }^{3}$ Although the concept of the dental home has rarely been studied, if access and utilization are used as indirect measures of the benefits of a dental home, then the concept has merit to improve the oral health of children. ${ }^{4}$ For instance, the institutions of Vadodara have a dental home setup in their premises where regular out patient department's (OPD) are
${ }^{1-6}$ Department of Pedodontics and Preventive Dentistry, KM Shah Dental College and Hospital, Sumandeep Vidyapeeth, Vadodara, Gujarat, India

Corresponding Author: Seema Bargale, Department of Pedodontics and Preventive Dentistry, KM Shah Dental College and Hospital, Sumandeep Vidyapeeth, Vadodara, Gujarat, India, Phone: +91 7016048359, e-mail: drseema9@yahoo.co.in

How to cite this article: Vaidya S, Bargale S, et al. Assessment of Knowledge and Awareness Regarding Dental Home among Pediatric Residents in Vadodara City, Gujarat, India: A Cross-sectional Study. J South Asian Assoc Pediatr Dent 2019;2(1):5-9.

Source of support: Nil

Conflict of interest: None

attended. The duty is on us to inform people sufficiently and timely as regard for preventing dental diseases.

In developing countries like India, pediatricians are typically the first medical professionals to be consulted as parents usually seek out their guidance in securing their child's normal growth and development. If proper counseling regarding the child's development and the eruption of teeth as well as guidance for the prevention of various oral diseases is rendered at this age, then better oral health can be obtained for these children. Pediatricians are considered to be in a unique position to provide preventive oral information and to diagnose oral diseases in their patients early on because of the early age at which children are brought to their offices. ${ }^{5}$ Thus, the aim of the study is to assess the knowledge about 
the awareness dental home concept among the pediatric residents in the city of Vadodara.

\section{Need for the Study}

After searching the literature regarding the awareness of the concept of dental home among pediatric residents, limited articles were found for the same. The medical pediatric residents, especially in public universities, being the first contact persons for most of the patients, play a major role in educating the parents and children on dental health and are expected to know about the concept and the scope of dental home. Thus, this study was undertaken to assess the awareness of the concept of dental home among the residents of private and public universities.

\section{Objectives of the Study}

- To assess the awareness of the dental home concept in residents of private universities of Vadodara city.

- To assess the awareness of the dental home concept in residents of public universities of Vadodara city.

- To compare the knowledge regarding the concept of dental home among the residents of private and public universities of Vadodara city.

\section{Materials and Methods}

This study was designed as a cross-sectional questionnaire study. The study was conducted after obtaining approval from the Institutional Ethical Committee (SVIEC/ON/Dent/SRP/18123). The sample size of the study was estimated to be 60 keeping the power of the study at $80 \%$ and $95 \%$ confidence interval. Prior permission was obtained from the Dean and Head of the Department of Pediatrics of respective institutes from where the sample was to be drawn. Sixty pediatric residents were enrolled in the study after obtaining informed consent from the participants, from two medical institutes of Vadodara, one being a private university (group I) and other a public university (group II). The study population was clearly identified, accessible, and reliable. The entire population was considered as the sample (population $=$ sample $=$ pediatric residents in Vadodara city). There were no dropouts in the study; thus, selection bias was eliminated. The interviewer bias was minimized by blinding principal investigator to the outcome of the interest of the study. The proforma of the study was distributed and explained to the participants in person by the principal investigator. Confounding factor such as discussion among the residents while filling the questionnaire was eliminated by restricting any discussion among residents by recording individuals' response in private. The questionnaire contained 12 custom-made questions (Annexure 1). Validation of the questionnaire was done using the content validity and concurrent validity techniques. It was a close-ended questionnaire. Among the questionnaire, the first five questions focused on general information about the pediatric residents. The next questions were framed to ascertain residents' familiarity with the concept of dental home and its characteristics and compared with those described by Nowak and Casamassimo. ${ }^{4}$

The participants were asked to fill the questionnaire to the best of their knowledge and contact the principal investigator if they faced difficulty in understanding any of the questions in the questionnaire. The filled proforma was then collected. The data compilation was done by the coinvestigator and submitted for statistical analysis. The statistician was blinded to the identification of the groups. The Chi-square statistical test was used for comparison between the two groups.

\section{Results}

On comparison between the two groups, questions 1-5 included questions which assessed pediatric residents' knowledge on issues like oral health and its association with general well-being, pediatricians' role in promoting oral health, examining and discussing oral cavity, and oral health problems as a part of routine childcare and the role of feeding habits with dental problems. It was found that answers were statistically nonsignificant with the Chi-square value of 0 and a $p$ value of 1 . The answers to question number 6 depicted the awareness of residents to the presence of a dental home in their institute and it was observed that the residents of the private university were more aware. It was observed that the public university residents referred more parents and patients to the dental home compared to the private university. However, both the groups showed statistically nonsignificant results, $p=0.301$ and $p=0.297$ (Figs 1 and 2).

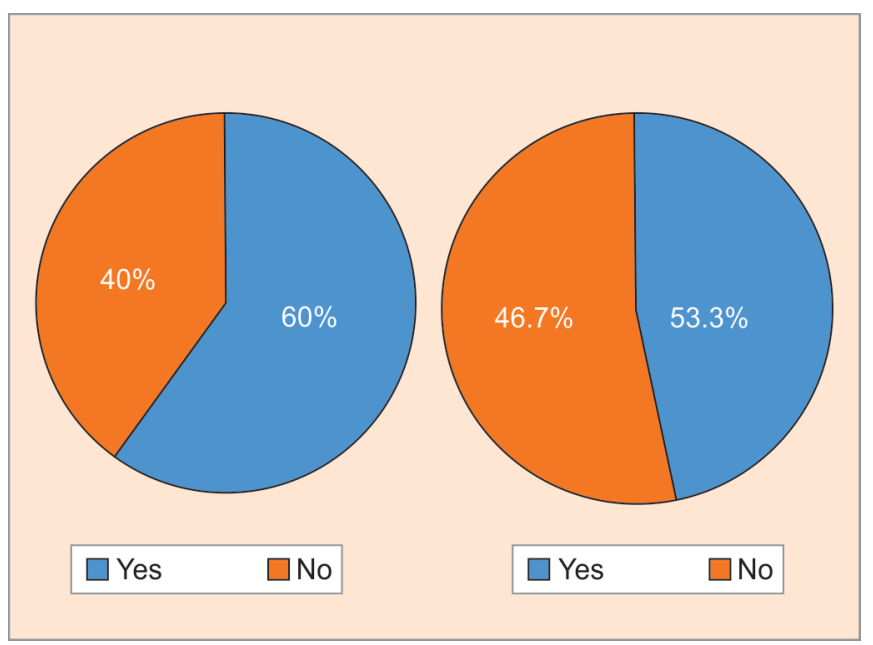

Fig. 1: Is there a dental home in your institution? Chi-square value$1.071, p$ value -0.30

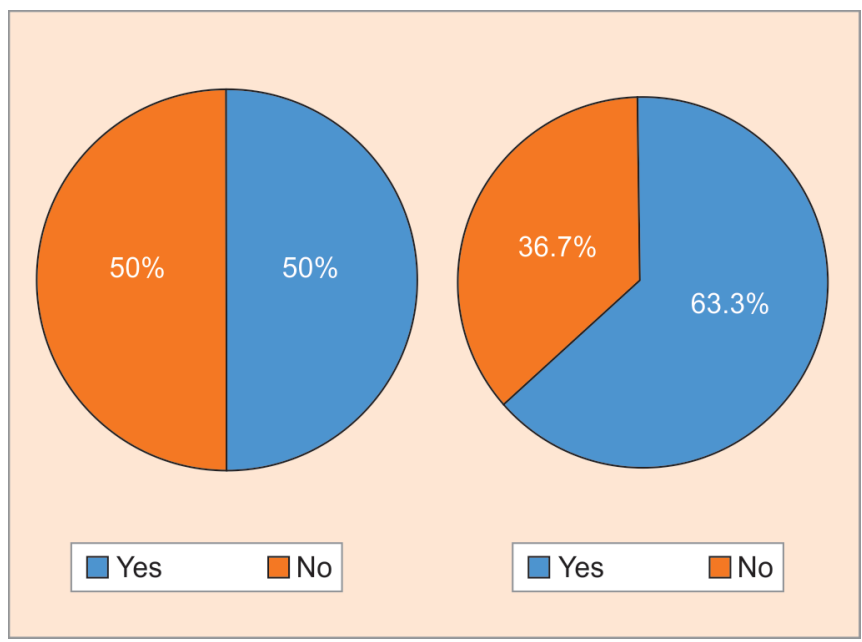

Fig. 2: Do you refer the infant to dental home if the infant has dental problems? Chi-square value-1.086, $p$ value -0.27 


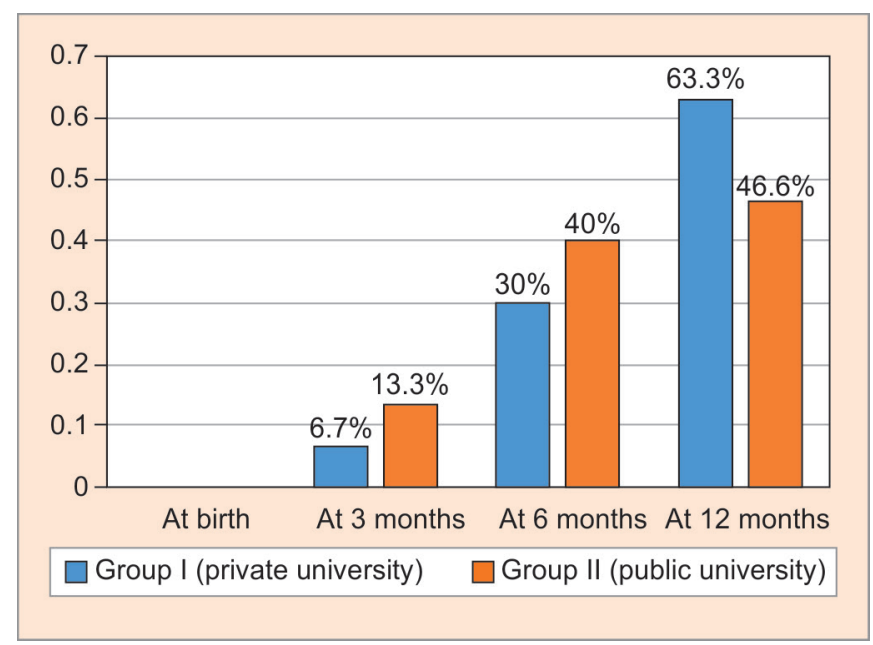

Fig. 3: Ideal time for the first referral of child to the dental home

Pediatric residents from both the institutes agreed about their role in promoting oral health. Participants in both the groups acknowledged the need to increase awareness regarding the concept of dental home. The results of the study revealed that $70 \%$ of the residents from a private institute and $60 \%$ of the residents from a public institute examined the oral cavity as a part of routine childcare. It was observed that $60 \%$ of the residents from the private institute confirmed about the awareness of the presence of dental home as compared to $53.3 \%$ in the public institute; however, this observation was statistically nonsignificant having $p$ value $=0.30$.

The next question was a multiple-choice question in which the pediatric residents were asked about the ideal time for the first dental visit/referral of the child to a dental home. AAPD guidelines recommend establishing a dental home for infants by 12 months of age. Figure 3 shows a bar diagram depicting that $63.3 \%$ of the residents from a private institution were aware of the ideal time for the first referral of the child to the dental home as compared to $46.6 \%$ of the residents in a public institute.

The next question assessed pediatric residents' knowledge regarding the association between prenatal counseling and dental home and the results revealed that $50 \%$ of the pediatric residents from their respective institutes were aware that prenatal counseling is an integral part of dental home. Figure 4 shows a bar diagram displaying different procedures that are performed in a dental home setup and its knowledge among pediatric residents in both the institutes. It was observed that information regarding the status of growth and development of the child, diet counseling, and diagnosis of dental caries was done almost equally in both types of universities. However, the residents of private university residents showed slightly higher precision in diagnosing dental caries but exhibited slightly lesser inclination toward counseling regarding the status of growth and development.

When immunization protocol and approach to trauma cases were compared, the public university had more residents taking into account the status of immunization (30\%) and trauma cases (27\%) when compared with the private university (13\%) and (16\%), respectively. Preventive measures such as topical fluoride application were found to be practiced more by the private university residents (40\%) when compared with the public university residents (13\%).

\section{Discussion}

The concept of dental home embraces the importance of early intervention and could provide optimal preventive strategies based on the risk of the patient. This study was conducted to elicit an insight of the dental home with stated standard policies and standard operating procedures (SOPs) in a way similar to the medical home which has made a mark with demonstrated benefits in medical literature. ${ }^{6-10}$ One of the objectives of this study was to test pediatric residents' awareness of the dental home. The results of the present study showed an overall lack of awareness about the concept of dental home. This survey indicates that pediatric residents strongly believed and acknowledged the importance of promotion of oral health and showed a willingness to incorporate the characteristics of dental home while making necessary and timely referrals of pediatric patients to a dental home. Most pediatric residents reported that they routinely assess a child's dental health. Relatively fewer pediatricians discussed about oral health with their parents. These results are in accordance with the study conducted in Ghaziabad city by Indushekhar et al., ${ }^{11}$ wherein only $12 \%$ of the pediatricians routinely performed oral examination of infants while doing a general physical examination of the child. The pediatricians gave nutritional counseling to the parents but only $4 \%$ of them counseled the parents about the risk of caries.

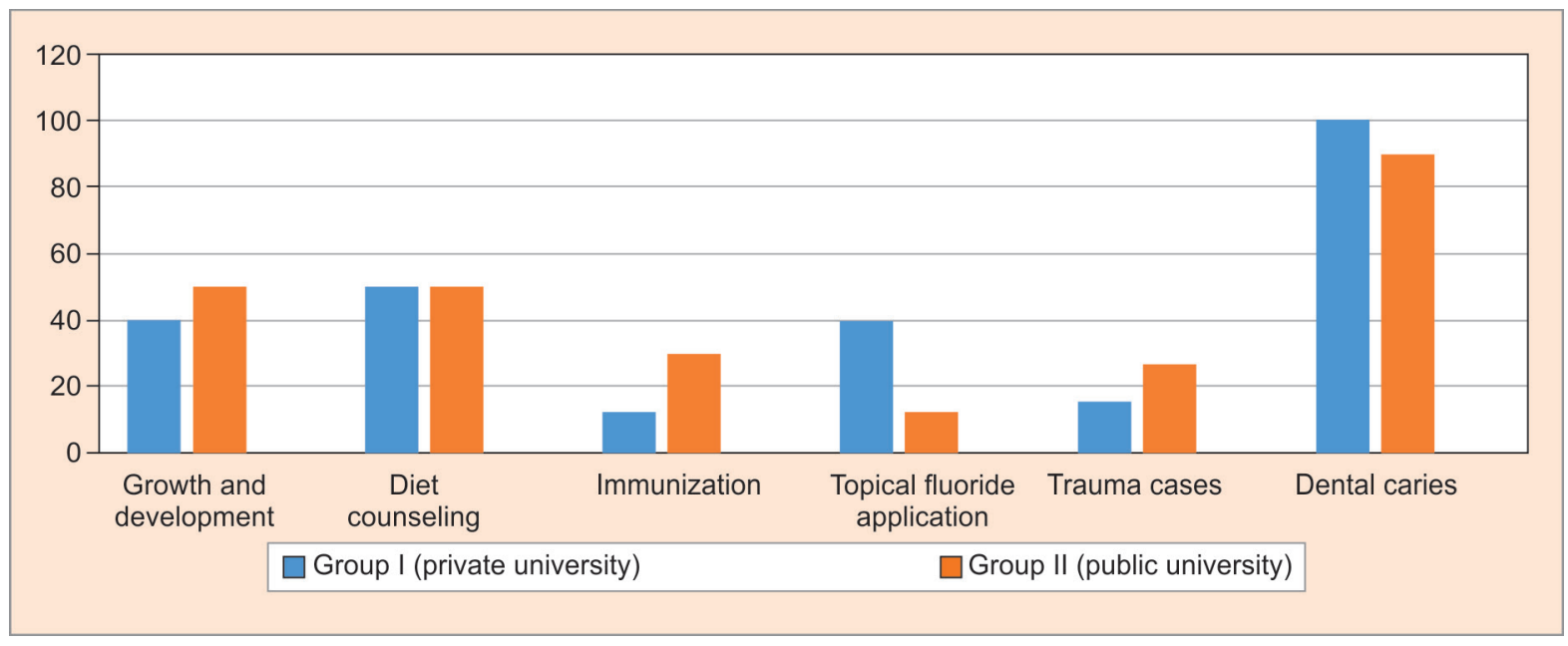

Fig. 4: Procedures performed in dental home 
A majority of pediatrician's encounter dental problems on a regular basis and are involved in the prevention of dental problems. However, only half of the pediatric residents confirmed their awareness regarding the presence of a dental home in their institute/hospital. The awareness was seen more among residents from a private institute as compared to a public institute. No particular reason could be attributed to the same. A majority of the pediatric residents in this study established a positive correlation between feeding practices with dental caries. Early recognition of dental caries and prophylactic measures against dental problems could prevent infection, dietary problems, missed school days, and poor quality of life. ${ }^{12}$ AAPD encourages the first dental visit by approximately 1 year of age ${ }^{4}$ and almost half of the pediatric residents were well versed by the fact. However, the awareness was seen more among residents from a private institute as compared to residents from a public institute. Half of the pediatric residents from both the institutes were mindful of the fact that prenatal counseling is a fundamental part of dental home and via prenatal counseling, pediatricians can discuss poor nutrition during pregnancy and low birth weight as risk factors of early childhood caries (ECC). Ramazani et al. in his study concluded that that medical practitioners like physicians should emphasize the importance of suitable nutrition during pregnancy because during this period, the enamel formation is to be started. ${ }^{13}$

Despite the optimistic and enthusiastic outlook displayed by the pediatric residents about incorporating characteristics about dental home in their routine practice, the survey identified some barriers that may limit pediatricians' effectiveness in the promotion of oral health in their practices. First, the sample size was inadequate to derive a substantial result. Second, pediatricians' knowledge of and familiarity with basic oral health-related issues were limited, particularly on topics where new information has emerged in the last decade. They exhibited incomplete knowledge when asked about the different procedures that were performed in the dental home setup. These results were similar to those found in the study conducted by Lewis et al. ${ }^{14}$ The dental home could increase opportunities for preventive oral health services for children that can reduce disease disparities. The concept of dental home requires support and further investigation so that in conjunction with the medical home, it could provide comprehensive health care to all children in our country. ${ }^{4}$

\section{Conclusion}

- This study helps us in concluding that there is a lack of knowledge and awareness about the prevention of dental caries among pediatric residents in Vadodara city.

- Early intervention through collaborative efforts of pediatric residents and pedodontists could address the emerging dental problems.
- The residents displayed positive attitude and practices; however, had moderate knowledge about dental caries.

- Regular lectures and dental health education programs pertaining to preventive strategies and the concept of dental home should be conducted and included in the postgraduate curriculum and published in medical journals.

\section{References}

1. https://www.census2011.co.in/census/city/338-vadodara.html/ Census 2011, Indian. "Indian Census 2011".

2. Hammersmith KJ, Siegal MD, et al. Ohio dentists' awareness and incorporation of the dental home concept. J Am Dent Assoc 2013 Jun 1;144(6):645-653. DOI: 10.14219/jada.archive.2013.0176.

3. Giriraju A, Lakshminarayan N. Dental Home: A Concept for Early and Everlasting Smile. Sch J Dent Sci 2017;4(3):121-124.

4. Nowak AJ, Casamassimo PS. The dental home: a primary care oral health concept. J Am Dent Assoc 2002 Jan 1;133(1):93-98. DOI: 10.14219/jada.archive.2002.0027.

5. Calonge NZ. U.S. Preventive Services Task Force. Prevention of dental caries in preschool children: recommendations and rationale. Am J Prev Med 2004;26:326-329. DOI: 10.1016/j.amepre.2004.01.008.

6. American Academy of Pediatric Dentistry. Policy on the Dental Home. Pediatr Dent 2009;31(6):22-23.

7. American Academy of Pediatric Dentistry. Definition of thedental home. American Academy of Pediatric Dentistry referencemanual 2012-2013. Pediatr Dent 2012;34(6 reference manual):12.

8. American Dental Association. Current Policies: Adopted 1954-2011Definition of Dental Home. Chicago: American Dental Association 2012. 85. www.ada.org/sections/about/pdfs/doc_policies.pdf, accessed March 25, 2013.

9. Academy of General Dentistry. Constituent Dental Care/Practice Chairperson's Resource Manual: September 2010_Dental Practice. www.agd.org/files/webuser/website/constituent/leaderduties/ constituentdentalcarechairpersonsmanual(updated_9-10)(sv).doc, accessed April 21, 2013.

10. Hale KJ. American Academy of Pediatrics Section on Pediatric Dentistry. Oral health risk assessment timing and establishment ofthe dental home. Pediatrics 2003;111(5, pt 1):1113-1116. DOI: 10.1542/ peds.111.5.1113.

11. Lochib S, Indushekar KR, et al. Knowledge, attitude and practices of paediatricians in Faridabad towards infant oral health care. Univ Res J Dent 2014;3:2.

12. Rajalingam S, Rani VL. A descriptive study on awareness about oral health among paediatric practitioners in kanchipuram district. J Pharm Bioallied Sci 2016 Oct;8(Suppl 1):S144. DOI: 10.4103/09757406.191945.

13. Ahmadi R, Ramazani N, et al. Molar incisor hypomineralization: a study of prevalence and etiology in a group of Iranian children. Iran J Pediatr 2012 Jun;22(2):245-251.

14. Lewis CW, Grossman DC, et al. The role of the pediatrician in the oral health of children: a national survey. Pediatrics 2000 Dec 1;106(6):1-7. DOI: 10.1542/peds.106.6.e84. 


\section{Annexure 1}

\section{Proforma for Collection of Data}

Year:

College:
Date:

Proforma No.:

\begin{tabular}{|c|c|c|c|}
\hline Sr. No & Questions & Yes & No \\
\hline 1. & Do you think proper oral health is an integral part of general well-being? & & \\
\hline 2. & Do you think pediatricians should have role in promoting oral health? & & \\
\hline 3. & Do you examine oral cavity for dental problems as a part of routine child care? & & \\
\hline 4. & Do you discuss about oral health problems with the parents? & & \\
\hline 5. & Do you think that there is a role of feeding habits for dental problems? & & \\
\hline 6. & Is there a dental home in your institution? & & \\
\hline 7. & If yes, do you refer the infant to dental home if the infant has dental problems? & & \\
\hline \multirow[t]{5}{*}{8.} & $\begin{array}{l}\text { What according to you is the ideal time for first dental visit/referral of the } \\
\text { child to dental house? Tick the most appropriate }\end{array}$ & & \\
\hline & At birth & & \\
\hline & At 3 months & & \\
\hline & At 6 months & & \\
\hline & At 12 months & & \\
\hline 9. & Is prenatal counseling a part of dental home? & & \\
\hline \multirow[t]{7}{*}{10.} & $\begin{array}{l}\text { Tick the procedure which you think are performed in dental home } \\
\text { (you can tick multiple options) }\end{array}$ & & \\
\hline & Growth and development assessment & & \\
\hline & Diet counseling & & \\
\hline & Immunization & & \\
\hline & Topical fluoride application & & \\
\hline & Acute cases of trauma & & \\
\hline & Dental caries & & \\
\hline 11. & Do you think there should be increased awareness regarding dental home? & & \\
\hline 12. & Does the current curriculum in pediatrics postgraduation promotes oral health care? & & \\
\hline
\end{tabular}

